\title{
Improving the Precision of Tree Counting by Combining Tree Detection with Crown Delineation and Classification on Homogeneity Guided Smoothed High Resolution $(50 \mathrm{~cm})$ Multispectral Airborne Digital Data
}

\author{
Masato Katoh $^{1, *}$ and François A. Gougeon ${ }^{2}$
}

1 Education and Research Center of Alpine Field Science, Faculty of Agriculture, Shinshu University, 8304 Minamiminowa-Vill, Nagano 399-4598, Japan

2 Pacific Forestry Center, Canadian Forest Service, Natural Resources Canada, 506 West Burnside Rd, Victoria, BC V8Z 1M5, Canada; E-Mail: fgougeon@nrcan.gc.ca

* Author to whom correspondence should be addressed; E-Mail: mkatoh@shinshu-u.ac.jp; Tel./Fax: +81-265-77-1642.

Received: 28 March 2012; in revised form: 4 May 2012 / Accepted: 5 May 2012 /

Published: 14 May 2012

\begin{abstract}
A method of counting the number of coniferous trees by species within forest compartments was developed by combining an individual tree crown delineation technique with a treetop detection technique, using high spatial resolution optical sensor data. When this method was verified against field data from the Shinshu University Campus Forest composed of various cover types, the accuracy for the total number of trees per stand was higher than $84 \%$. This shows improvements over the individual tree crown delineation technique alone which had accuracies lower than $62 \%$, or the treetop detection technique alone which had accuracies lower than $78 \%$. However, the accuracy of the number of trees classified by species was less than $84 \%$. The total number of trees by species per stand was improved with exclusion of the understory species and ranged from $45.2 \%$ to $93.8 \%$ for Chamaecyparis obtusa and C. pisifera and from $37.9 \%$ to $98.1 \%$ for broad-leaved trees because many of these were understory species. The better overall results are attributable primarily to the overestimation of Pinus densiflora, Larix kaempferi and broad-leaved trees compensating for the underestimation of $C$. obtusa and $C$. pisifera. Practical forest management can be enhanced by registering the output resulting from this technology in a forest geographical information system database. This approach is mostly useful for conifer plantations containing medium to old age trees, which have a higher timber value.
\end{abstract}


Keywords: forest resource management; individual tree crown; tree counting method

\section{Introduction}

Forests in Japan cover approximately 25.10 million ha or $66 \%$ of the total land area. Of these, 10 million ha $(\sim 40 \%)$ are artificial and plantations over 50 years account for about $35 \%$ of this area. The majority of plantations are dominated by conifers, with Cryptomeria japonica (Japanese Cedar), Chamaecyparis obtuse (Hinoki cypress), Chamaecyparis pisifera (Sawara cypress), Pinus densiflora (Japanese red pine), and Larix kaempferi (Japanese larch) being commonplace. Plantations aged between 31 and 60 years are managed by thinning or selective cutting or are harvested for timber, biomass and provision of clean energy [1]. Forest officers and landowners require accurate information on the number and distribution of tree species to support management of their plantation resources. The number of trees and distribution of each tree species are basic information that can be used to evaluate current stand conditions in forest management.

At present, field surveys for forest resource management count the number of trees and measure the diameter at breast height $(\mathrm{DBH})$ in small sample plots $(0.1 \mathrm{ha})$. Usually $3-5$ plots are located in each compartment. The structure of the entire forest resource is estimated by multiplying these measured values by the total forest area. However, this method is less accurate in large forests where stand conditions, species and stem densities vary. Although the number of study plots could be increased for greater accuracy, this would require a great deal of labor and cost. In addition, management operations have been abandoned in some forests following timber price decreases and as landowners age and retire. Forestry officers and landowners therefore need more accurate information on forest resource conditions.

The purpose of this study was to develop an economical method for estimating the number of trees of each dominant species over large areas using remote sensing data. Satellites are advantageous, as they can continuously capture data in multiple areas. The commercial satellites IKONOS, QuickBird, Geoeye-1 and WorldView-2, which have high spatial resolutions of $1 \mathrm{~m}$ or less in panchromatic mode, were launched in 1999, 2001, 2008 and 2009 respectively. As a result, the acquisition of detailed forest information from space has become possible and may be a more effective way to assess large areas of forest cover. Beginning in 2009, airborne remote sensing with high-resolution digital images taken over five years throughout the whole forest area of Japan has replaced previous analog aerial photographs.

Forestry studies with high-resolution airborne data have been successful in Canada and the United States [2-5]. Tree counting, tree-crown delineation, species identification, crown density estimation and forest stand polygon delineation have been made possible with high-resolution data such as that collected via the airborne Multi-detector Electro-optical Imaging Sensor (MEIS), the Compact Airborne Spectrographic Imager (CASI) and the Leica Airborne Digital Sensor (ADS)-40 or 80. Tree counting techniques are based mainly on detecting local maxima in a smoothed image of the coniferous forested area [6-8], provided that the detection filter size and smoothing of the image are appropriate to the tree size and image spatial resolution [9-11]. 
Techniques for tree-crown delineation are often based on first finding local maxima and then locating crown edges. A fundamental assumption inherent to crown delineation methods is that the main part of a crown is brighter than the lower edge of the crown, particularly at the boundary between crowns. Methods for delineating tree crowns include three main approaches: bottom-up, top-down, and template-matching algorithms. Top-down algorithms can be divided into watershed, multiple-scale edge segments, threshold-based spatial clustering, and double aspect methods. The template-matching algorithms match a synthetic image model or template of tree crowns with the image radiometric values [12-14]. The valley-following method [15] used in the present study is a bottom-up algorithm. Many examples of its application can be found in mature Canadian conifer forests.

In Japan, tree counting and tree-crown delineation methods have been applied to high-resolution airborne data from Japanese conifer plantations [16]. In this study, the accuracy of the image analysis was verified by comparing tree counts or maps of delineated crowns to detailed field-based inventories. This approach is more effective in delineating tree crowns forming the upper canopy of plantations comprised purely of coniferous species, although accuracies were $<60 \%$.

A representation of how tree crowns and their tops are viewed from the ground and from overhead is given in Figure 1. Here, three tree crowns seen from above are mistakenly counted as one large tree crown. On the other hand, tree numbers obtained by the tree counting method (treetop) often exceed the number of trees in field surveys, as spurious multiple treetops are often extracted from single tree-crowns or from canopy gaps showing the forest floor. Furthermore, the identification of treetops from point data is less reliable.

Thus, we devised an improved method of extracting the number of trees of each species by combining the advantages of both methods. Furthermore, this method of automatically counting trees by species within forest polygons was developed using the framework of commonly available GIS software, because the digitization of forest information has progressed with the use of GIS in Japan.

Figure 1. Treetops and tree crowns. (a) Trees seen from the side. (b) Trees seen from the air.

(a)

Tree tops

(b)

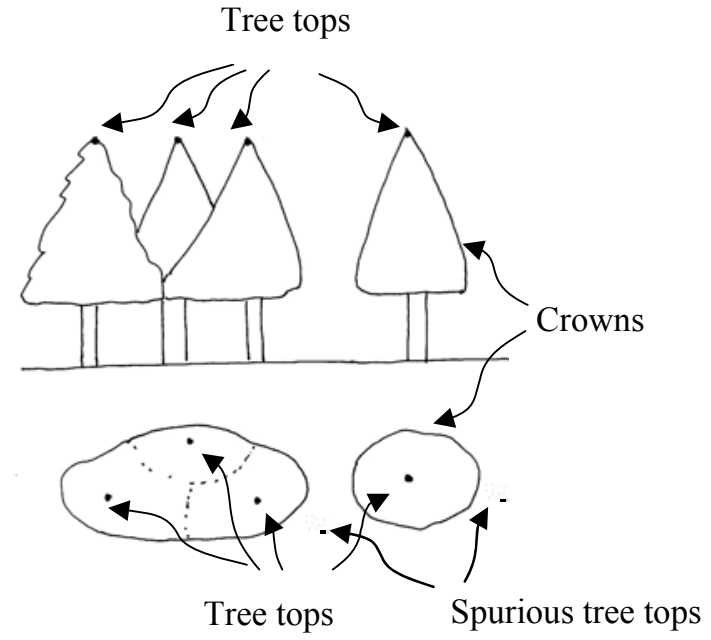




\section{Materials and Methods}

\subsection{Study Area}

The study area is part of the campus forest of the Faculty of Agriculture at Shinshu University, Nagano Prefecture, central Honshu Island, Japan $\left(35^{\circ} 51^{\prime} \mathrm{N}, 138^{\circ} 56^{\prime} \mathrm{E}\right.$, Figure 2). The campus forest, which is in the village of Minamiminowa, Kamiina District, Nagano Prefecture, is located at an altitude of $770 \mathrm{~m}$ above sea level and the area consists of undulating terrain and flat land. The campus covers 52.7 ha, 15 ha of which is occupied by high density conifer plantations, in which the dominant tree species are C. obtusa (Co), C. pisifera (Cp), P. densiflora (Pd), L. kaempferi (Lk), C. japonica $(\mathrm{Cj})$, and broad-leaved trees [16]. The age of plantations ranges from 24 to 86 years old and trees are typically 8 to $36 \mathrm{~m}$ in height and 2.1 to $13.5 \mathrm{~m}$ in crown diameter (Table 1 ).

Figure 2. Study area at the Shinshu University Campus forest in Nagano Prefecture, central Honshu Island, Japan.
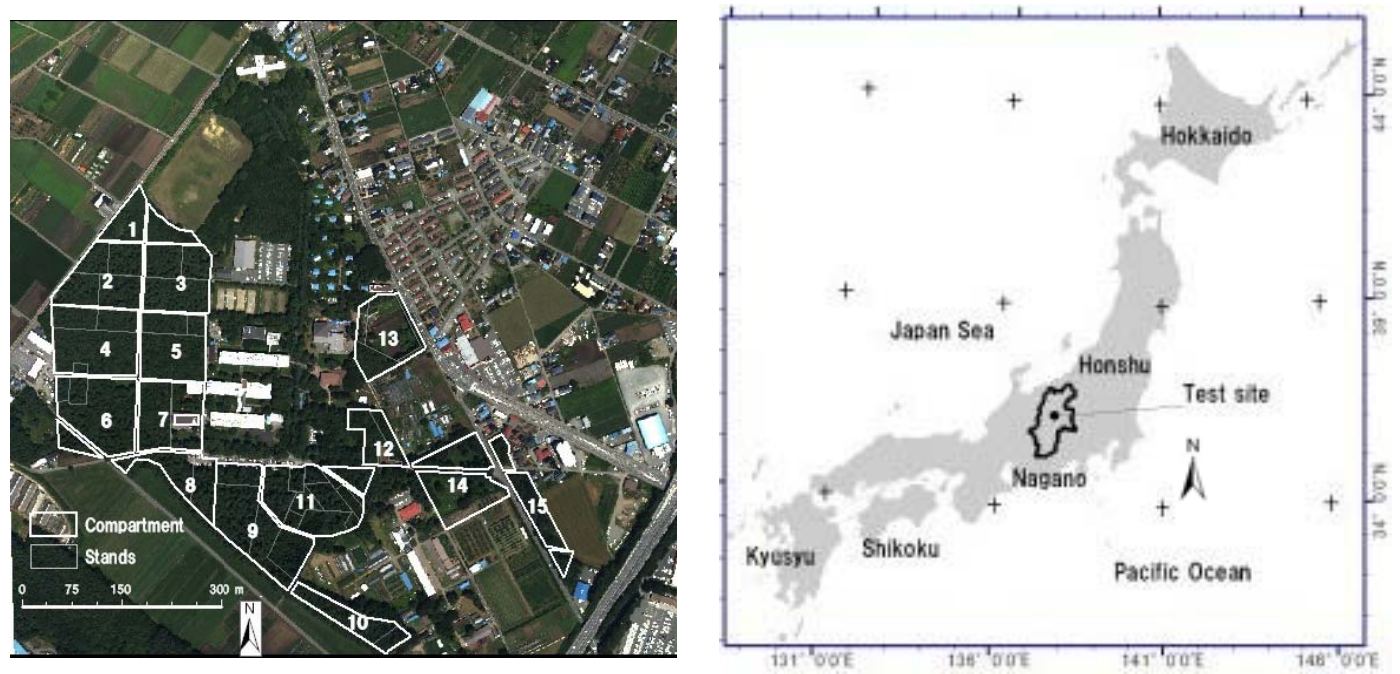

Table 1. Conditions and abbreviations of conifers investigated in this study.

\begin{tabular}{lcccc}
\hline Scientific Name & Age & DBH* $(\mathbf{c m})$ & $\mathbf{H}^{* *}(\mathbf{m})$ & CD***(m) $^{* *}$ \\
\hline Conifers $(\mathrm{N})$ & & & & \\
Chamaecyparis obtusa $(\mathrm{Co})$ & $28-77$ & $16-50$ & $13-26$ & $2.6-6.7$ \\
Chamaecyparis pisifer $(\mathrm{Cp})$ & $42-67$ & $8-45$ & $5-21$ & $2.1-6.0$ \\
Pinus densifolia $(\mathrm{Pd})$ & $46-86$ & $30-80$ & $17-27$ & $5.1-13.5$ \\
Lalix kaempferi $(\mathrm{Lk})$ & $51-86$ & $30-55$ & $20-31$ & $3.1-8.9$ \\
Cryptomeria japonica(Cj) & $24-86$ & $14-49$ & $13-25$ & $3.5-6.1$ \\
Broad leaved trees (BL) & - & $8-126$ & $8-25$ & $1.3-10.2$ \\
\hline
\end{tabular}

* Diameter at breast height; ** Tree Height; *** Crown Diameter.

\subsection{Airborne Digital Data}

The airborne sensor system used in the present study was developed by PASCO Corporation and contains an UltraCamD (UCD) constructed by Vexcel Co. Image data were acquired on 28 July 2005 
during clear weather conditions. The multispectral data of the full-size image consisted of four bands (visible blue, green, red, and near infrared) of 3,680 lines $\times 2,400$ pixels at nadir, stored as 16-bit data. The original images with sensor orientation, topographic relief displacement, and systematic errors were rectified by ortho-correction based on $\mathrm{X}, \mathrm{Y}$, and $\mathrm{Z}$ values for sensor positions derived from a GPS system and the principal points and focal length of the sensor. The geographic projection was converted to Japan JGD2000 Zone 8. The ground resolution of the multi-image was $50 \mathrm{~cm}$ after correction. Image processing and analysis were performed using ortho-correction processing with ERDAS IMAGINE 8.6 [17] and a tree-based stand map on field data, which was processed with ArcGIS 9.3 [18]. Treetop detection and tree-crown delineations were performed using the Individual Tree Crown (ITC)-Suite [19] and Geomatica 9 [20].

\subsection{Field Data Collection}

The field investigation was conducted from April 2005 to June 2010. Detailed stand information was available for forest compartments $1-7$, where all trees $\geq 8 \mathrm{~cm}$ in diameter at breast height (DBH) were measured. The survey noted species, $\mathrm{DBH}$, height $(\mathrm{H})$, tree position, and strata (upper, intermediate, or understory layer). The two-story plantations, in which young C. obtusa or C. japonica were planted under older $P$. densiflora stands, were high density. Species, age, compartment area, count, average DBH and height, timber volume, and growth per hectare were summarized by forest compartment (Table 2). C. obtusa, P. densiflora, and L. kaempferi stands ranged in age from 24 to 86 years; in timber volume from 426 to $509 \mathrm{~m}^{3}$; and in crown density from seven to nine, with high timber volume and high tree density.

Table 2. Forest resource conditions of the seven compartments in the study area at Shinshu University Campus Forest.

\begin{tabular}{clcccccccc}
\hline Compart. & Species** & & Area & Count & BH & H* & Volume & Growth & Crown \\
\hline No. & & Age & (ha) & /ha & $\mathbf{( c m )}$ & $\mathbf{( m )}$ & $\left.\mathbf{( m}^{3}\right)$ & $\left.\mathbf{( m}^{3}\right)$ & Density \\
\hline 1 & Pd, Lk, BL & $46-51$ & 0.58 & 687 & 13.7 & 15.6 & 462 & 3.45 & 9 \\
2 & Pd, Co, Lk, Cp, Co, BL & $46-58$ & 1.06 & 789 & 23.7 & 18.6 & 509 & 8.56 & 9 \\
3 & Lk, Pd, Cj, Cp, Co, BL & $26-63$ & 1.00 & 684 & 21.3 & 19.5 & 474 & 6.86 & 9 \\
4 & Co, Pd, Lk, Cp BL & $24-86$ & 1.17 & 910 & 23.6 & 16.0 & 504 & 10.2 & 7 \\
5 & Co, Pd, Cp, Cj, Lk, BL & $36-66$ & 1.00 & 856 & 23.8 & 16.5 & 481 & 7.30 & 7 \\
6 & Co,Pd, Cj, Lk, BL & $36-76$ & 1.25 & 673 & 23.6 & 16.0 & 470 & 7.28 & 9 \\
7 & Co,Pd, Cp, Co, Lk, BL & $31-66$ & 0.72 & 638 & 27.2 & 17.2 & 426 & 3.50 & 9 \\
\hline
\end{tabular}

* DBH, H showed the average value of majority species; **For species names, see Table 1 .

\subsection{GIS Data}

Forest compartment boundaries, forest roads, forest survey data, and geographic data such as contour lines on the forest base map (scale 1:5,000) of the campus research forest were included in the forest database. All tree positions in forest compartments 1-7 from the field survey were transferred and registered in the forest database using GIS [16]. 


\subsection{Methods}

The flowchart in Figure 3 provides an overview of methods. The general steps used in this study were as follows:

Figure 3. Overview of the approach.

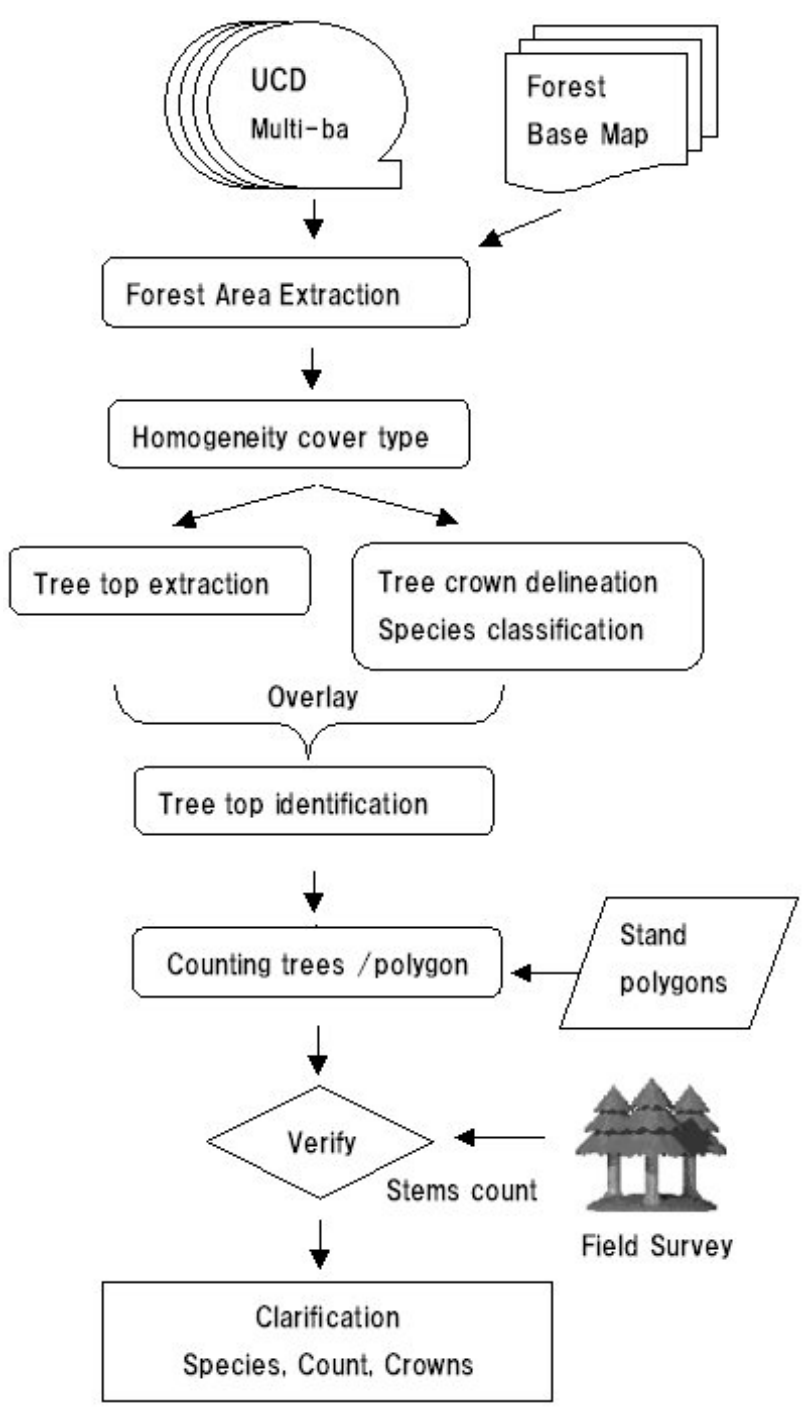

Forested areas were extracted using forest boundaries from the GIS database to separate them from non-forested areas, such as roads, grass areas, and artificial structures.

(1) Homogeneous cover-type regions were separated by textures or gray levels, which were reflecting tree species and crown sizes. The diameters of the tree crowns ranged from 3 to $10 \mathrm{~m}$; small tree areas were designated as those with tree crowns of 3 to $5 \mathrm{~m}$, and large tree areas were those with crowns of 5 or more meters. Next, small tree-crown areas were smoothed on the image with a $3 \times 3$ average pixel filter; and large tree areas with an additional $5 \times 5$ pixel filter.

(2) Treetops were extracted with the local maxima filtering technique with a $3 \times 3$ window $[8,9,19]$.

(3) Individual tree-crown (ITC) delineations were extracted by the valley-following technique $[3,15,19]$. 
(4) ITCs were classified into species using a supervised classification process based on comparing multi-spectral crown signatures with a maximum likelihood decision rule $[16,19]$.

(5) The existing two methods of "Tree top detection" and "ITCs species classification" were combined in the new technique. Tree top pixels were identified to species by overlaying them onto the ITC classification and thus, spurious treetops from canopy gaps or shaded areas were removed. These pixels were transferred from a pixel to point data using "raster to vector" conversion function, and then automatically labeled.

(6) The number of trees by species within forest stand polygons was semi-automatically counted.

(7) The data derived from these techniques were registered in a forest database and compared with the field investigation data to verify the effectiveness of this approach.

\section{Results and Discussion}

\subsection{Homogeneity Cover Type}

Homogeneous cover type analysis separated regions with different textures or gray levels by tree species and crown size. Small tree areas were extracted by blocking out large tree areas (Figure 4). Small tree crown areas were smoothed separately with a $3 \times 3$ average filter, and large tree areas were smoothed with a $3 \times 3$ and then a $5 \times 5$ averaging filter.

Figure 4. A texture homogeneity measure criteria is used to separate small tree areas from big tree.

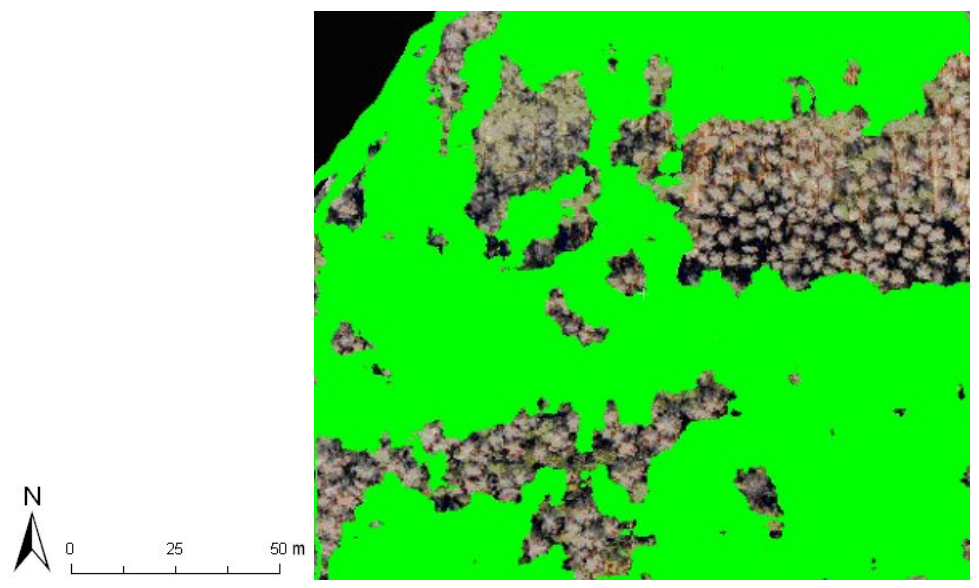

\subsection{Identification of Tree Species}

The ITC isolation image was produced using valley-following procedures. The ITC isolation image and multi-spectral images were fed into a supervised classification process to identify species [16]. Treetops were overlain onto the ITC classification image (Figure 5(a)) and then associated with a species semi-automatically based on their correspondence to the ITC classification image. Through this process, spurious treetops in the valley and canopy gaps were excluded as they did not correspond to a class. An example classification showing the distribution of treetops by species and relative differences in density is given in Figure 5(b). Patches of C. obtusa, P. densiflora, and L. kaempferi were clear, indicating a good representation of conifer plantations in the area. 
Figure 5. Identification of tree species (a) Treetops as red crosses overlaid on the individual tree-crown (ITC) species classification. (b) Treetops species identified using a combined ITC approach and treetop extraction method.

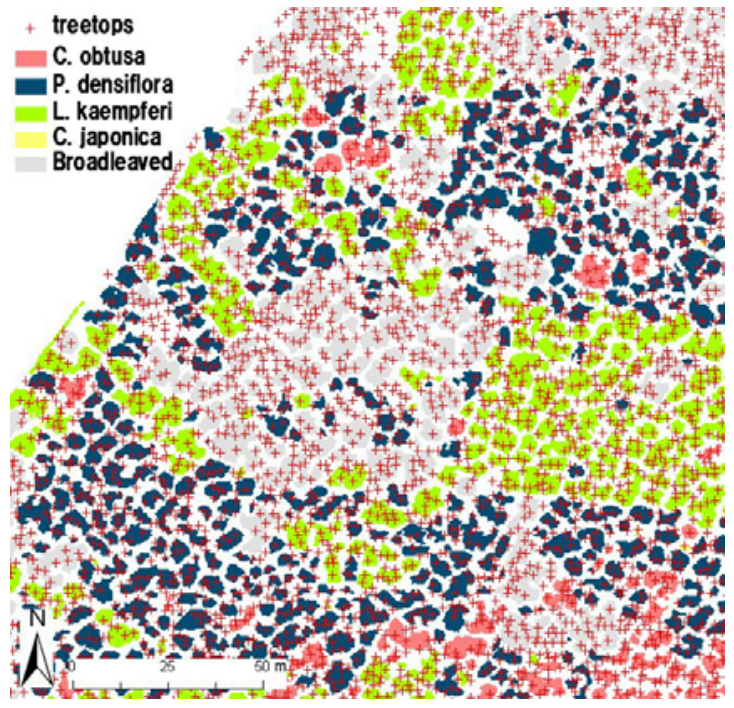

(a)

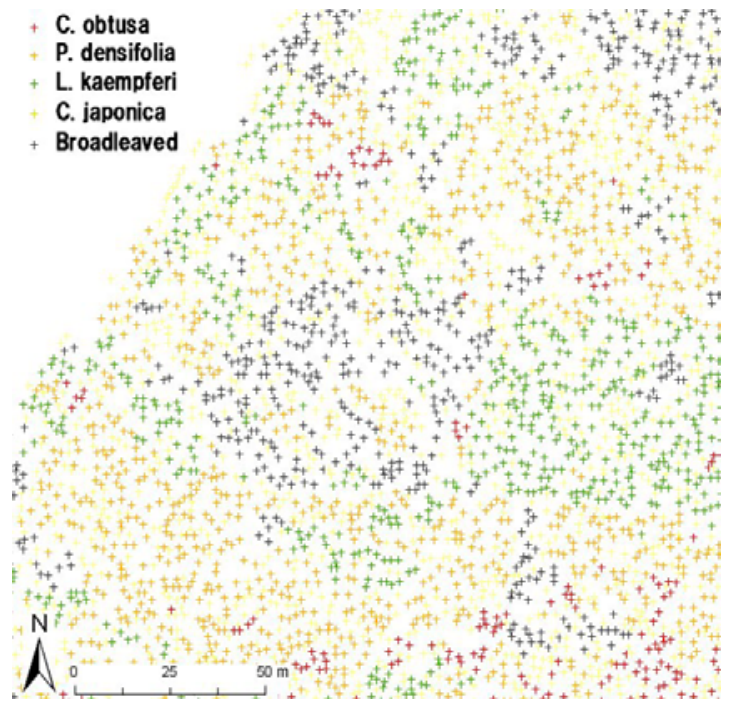

(b)

Figure 6. Automated tree species count per stand polygon, using GIS functions. Counted data were registered in a forest database, shown in the stand table.

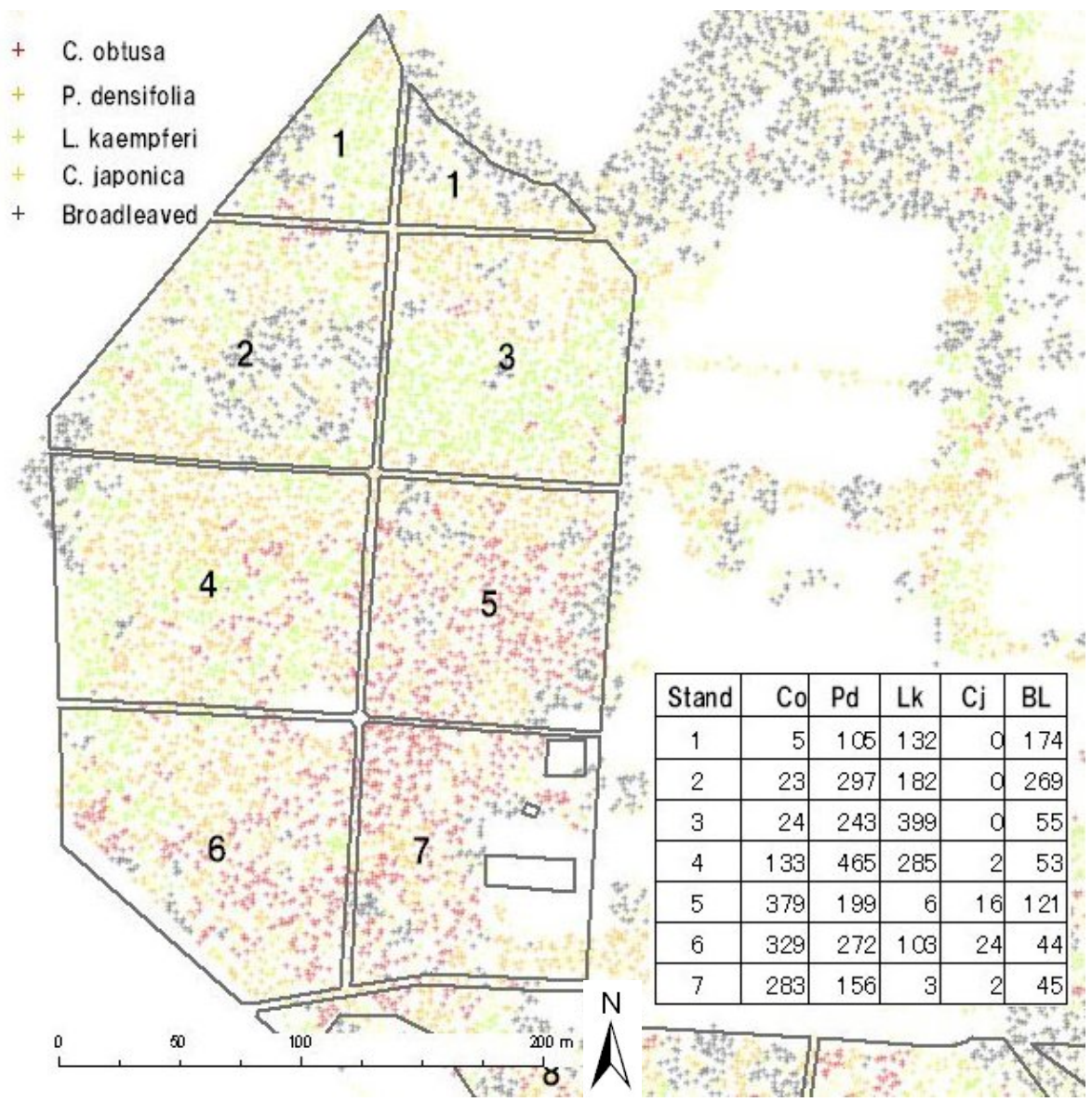




\subsection{Generating Treetop Information for Forest Compartments}

A count of the number of trees associated with each species within delineated forest stands was undertaken (e.g., Figure 6) from which a stand map representing dominance of species and the density of stems was generated.

The mapping can be used to support forest management. In the example (Figure $7(a, b)$ ), the mapping highlights stands that were dominated by C.obtusa, which has a higher timber value compared to others within stands. The mapping can be used to inform on actions such as thinning. A map of tree positions within each of three strata is given in Figure 7(b).

Figure 7. (a) Species and stem locations, with C. obtusa trees indicated by large red points overlaid on true color composite image. (b) Map of tree positions within each of three strata(upper, intermediate and understory) from field data.

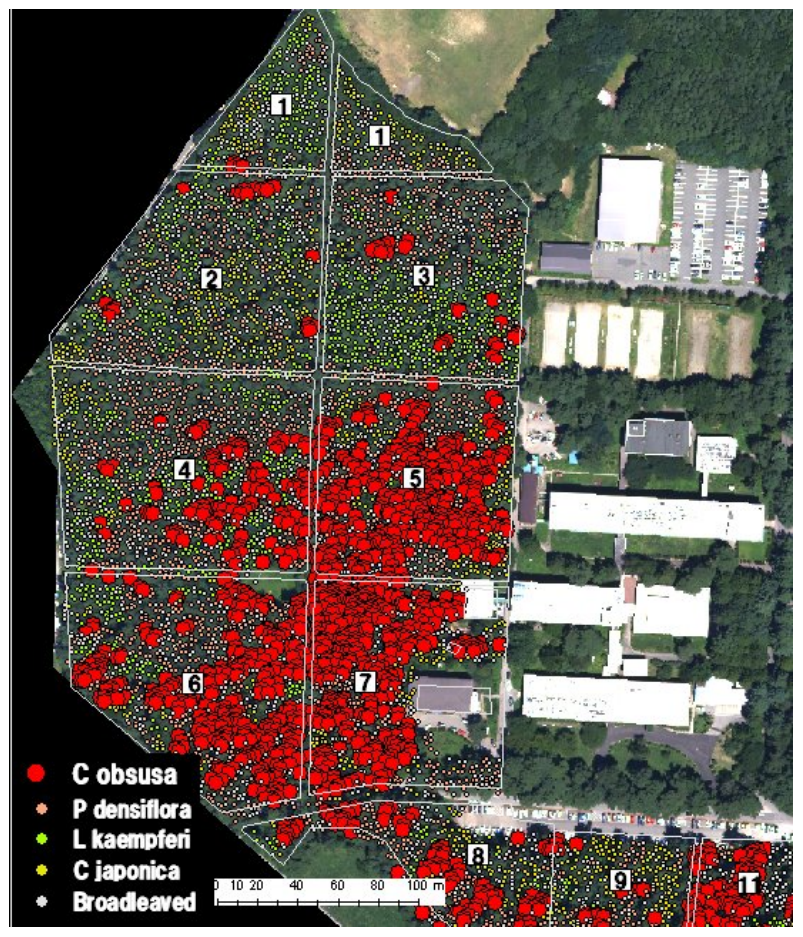

(a)

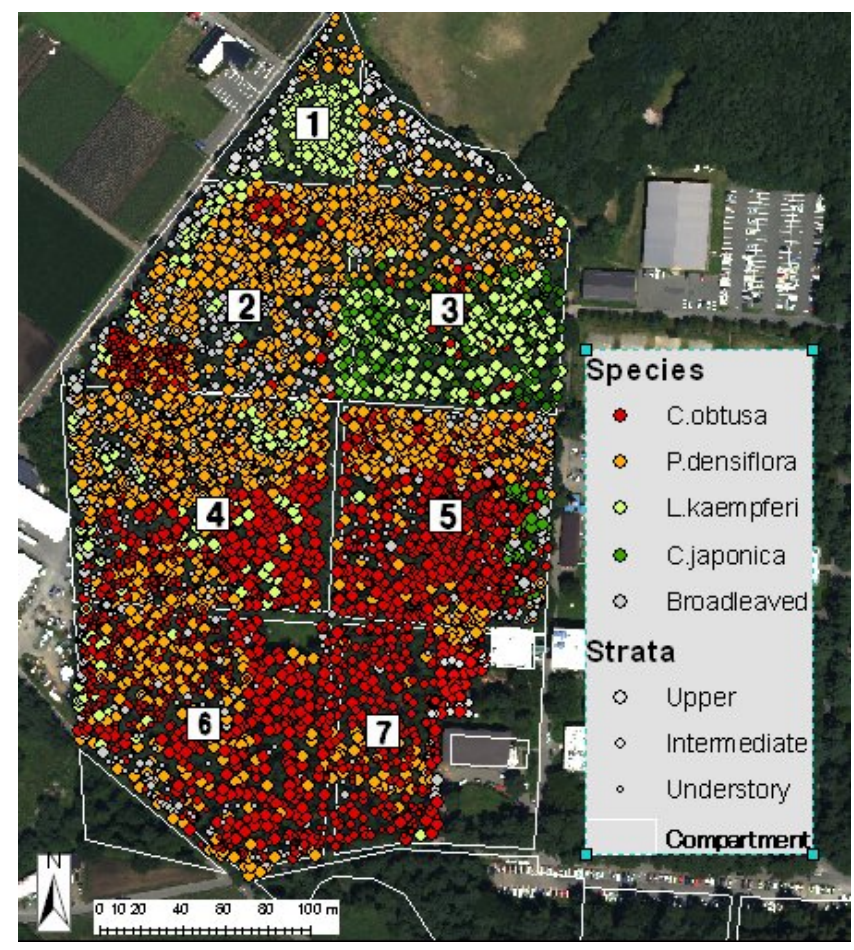

(b)

\subsection{Verification Based on Field Investigations}

A comparison of the locations of the stems of $C$. obtusa trees identified using the tree top counting technique within seven forest compartments with those mapped through field survey indicated a close correspondence (for those $\geq 8 \mathrm{~cm} \mathrm{DBH}$ ) (Table 3). Three counts of trees were compared against the field data; treetops identified using local maxima filtering within the smoothed image, crowns identified using the ITC delineation and both treetops and crowns identified using a combined technique. The number of stems ranged from 399 to 1,065; treetops, from 647 to 1,381; crowns, from 201 to 387; and treetops generated by the new technique, from 416 to 938 .

The treetop counts were more than that of the field stems, whereas the crown counts were less than that of the field stems. The error rate between the treetop counts and the stems counted in the field 
ranged from $22.4 \%$ to $62.2 \%$. The error rate between the crown counts and the stems counted in the field ranged from $-38.6 \%$ to $-74.5 \%$. On the contrary, the error rate between the numbers of treetops extracted with the new technique (NT) and stems from the field investigation ranged from $2.3 \%$ to $-15.8 \%$, showing that this method leads to improved accuracy over treetop and crown delineation used separately in stands 1,3 and 7.

Table 3. Comparison of ground survey data with image analysis of the seven compartments.

\begin{tabular}{ccccccccc}
\hline Stand & \multicolumn{8}{c}{ Total } \\
\hline No. & Area (ha) & Stems & Tree Tops & Crowns & New Tech. & TT-Error & CR-Error & NT-Error \\
1 & 0.58 & 399 & 647 & 245 & 416 & 62.2 & -38.6 & 4.3 \\
2 & 1.06 & 837 & 1098 & 370 & 771 & 31.2 & -55.8 & -7.9 \\
3 & 1.00 & 684 & 1040 & 337 & 721 & 52.0 & -50.7 & 5.4 \\
4 & 1.17 & 1065 & 1381 & 387 & 938 & 29.7 & -63.7 & -11.9 \\
5 & 1.00 & 856 & 1048 & 317 & 721 & 22.4 & -63.0 & -15.8 \\
6 & 1.25 & 842 & 1067 & 215 & 772 & 26.7 & -74.5 & -8.3 \\
7 & 0.72 & 478 & 721 & 201 & 489 & 50.8 & -57.9 & 2.3 \\
Total & 6.78 & 5161 & 6602 & 2072 & 4828 & 27.9 & -59.9 & -6.5 \\
\hline
\end{tabular}

Stems: Count of trees from field survey; Tree tops: Count of tree tops from image analysis; Crowns: Count of Crowns from image analysis; New tech.: Count of treetops using new technique from image analysis; TT-Error. : (Treetops - Stems) $\div$ Stems $\times 100$; CR-Error.: (Crowns - Stems) $\div$ Stems $\times 100$; NT-Error. : (New tech. - Stems $) \div$ Stems $\times 100$.

In stands $2,4,5$, and 6 , the number of new technique treetops was slightly lower than that of stems from field survey data. These data indicate that it is difficult to extract treetops using image analysis, because these are two-storied stands with upper-story trees of L. kaempferi and P. densiflora and understory trees of C. obtusa and broad-leaved trees, which occurred as small-diameter crowns under the upper tree crowns. Stand 7 had the lowest error rate $(2.3 \%)$, probably because the sharp, conical crowns of the dominant upper-story trees, C. obtusa and C. pisifera, were easier to extract using image analysis compared with crowns of other tree species [16].

Table 4 lists the numbers of stems and tree crowns, and the results of the New Treetop Technique by tree species (NTT). Generally, the number of crowns from the image analysis was fewer than that of stems from the field survey, primarily because some trees in the image were misidentified as one large tree crown rather than a cluster of trees. However, the new image analysis yielded treetops closer to the number of stems from field survey. Stem errors were derived from these data for accuracy verification.

Two types of stem errors were derived from these data for accuracy assessments, the later one (NTT-error 2) excluding understory stems. From the field survey, 118 of the 399 trees in stand 1 were L. kaempferi, and 252 of the 837 trees in stand 2 were P. densiflora. Of the 684 trees in stand 3, 186 were L. kaempferi and 152 were $P$. densiflora. In stands 4, 5, 6, and 7, C. obtusa and C. pisifera were dominant, with numbers of trees ranging from 352 to 554. Of the numerous broad-leaved trees, the majority was understory and intermediate trees; the numbers of broad-leaved understory trees ranged from 26 to 252 in all stands. The numbers of planted C. obtusa trees ranged from 29 to 194 in stands 2, $4,5,6$, and 7, which were two-storied plantations. Planted C. japonica trees were mainly understory trees in stands 3 and 5 with 73 trees and 35 trees. 
Compared with the respective numbers of stems from the survey, the numbers of $C$. obtuse, C. pisifera, and broad-leaved treetops determined using the new technique were lower, and the numbers of $P$. densiflora and L. kaempferi treetops were higher.

The error rates for treetops by tree species between NTT and stems from the field investigation are shown as NTT errors in Table 4. The error rates for C. obtusa and C. pisifera ranged from $-16.0 \%$ to $-89.6 \%$, except in stands 1 and 3, where fewer of these trees grew. The error rates ranged from $15.7 \%$ to $183.6 \%$ for $P$. densiflora, from $11.9 \%$ to $487.1 \%$ for $L$. kaempferi, and from $-33.3 \%$ to $-100.0 \%$ for C. japonica. For the broad-leaved trees, the error rates ranged from $-19.0 \%$ to $-82.4 \%$.

In stands 2, 4, 5, 6, and 7, there were fewer C. obtusa and $C$. pisifera treetops compared with the numbers of stems from the field survey because many of these were understory trees. However, there were more $P$. densiflora and $L$. kaempferi treetops compared with the numbers of stems because, owing to their large crowns, one crown was sometimes misidentified as a cluster of crowns. The error rate of the new technique, excluding understory stems, was obviously improved, as shown by NTT error 2 in Table 4. The error rates for total numbers of $C$. obtusa and C. pisifera trees per stand, excluding understory stems, ranged from $-6.2 \%$ to $-55.8 \%$, and error rates for broad-leaved trees ranged from $8.2 \%$ to $63.1 \%$. The results for multilayered or two-storied stands were inferior to those of single layer stands or pure conifer plantations because multilayered stands have some intermediate or understory trees that are difficult to extract using image analysis.

Table 4. Comparison between ground survey and the new technique data by species in the seven compartments.

\begin{tabular}{|c|c|c|c|c|c|c|c|c|c|c|c|c|}
\hline \multirow{2}{*}{$\begin{array}{c}\text { Stand } \\
\text { No. }\end{array}$} & \multicolumn{4}{|c|}{ Total } & \multicolumn{8}{|c|}{$\mathrm{Co}+\mathrm{Cp}$} \\
\hline & Stems & Crowns & \multicolumn{2}{|c|}{ New tech. } & Stems & \multicolumn{2}{|c|}{ Under stems } & \multicolumn{2}{|c|}{ Crowns NTT } & NTT-error & \multicolumn{2}{|c|}{ NTT-error2 } \\
\hline 1 & 399 & 245 & \multicolumn{2}{|c|}{416} & 5 & \multicolumn{2}{|l|}{0} & 8 & 5 & 0.0 & \multicolumn{2}{|c|}{0.0} \\
\hline 2 & 837 & 370 & \multicolumn{2}{|c|}{771} & 222 & \multicolumn{2}{|l|}{194} & 18 & 23 & -89.6 & \multicolumn{2}{|c|}{-17.9} \\
\hline 3 & 684 & 337 & \multicolumn{2}{|c|}{721} & 13 & \multicolumn{2}{|l|}{0} & 17 & 24 & 84.6 & \multicolumn{2}{|c|}{84.6} \\
\hline 4 & 1065 & 387 & \multicolumn{2}{|c|}{938} & 377 & \multicolumn{2}{|l|}{76} & 82 & 133 & -64.7 & \multicolumn{2}{|c|}{-55.8} \\
\hline 5 & 856 & 317 & \multicolumn{2}{|c|}{721} & 451 & \multicolumn{2}{|l|}{47} & 137 & 379 & -16.0 & & 5.2 \\
\hline 6 & 842 & 215 & & 172 & 554 & 77 & & 85 & 329 & -40.6 & & 1.0 \\
\hline 7 & 478 & 201 & & 189 & 352 & 29 & & 141 & 283 & -19.6 & & 2.4 \\
\hline Total & 5161 & 2072 & & 828 & 1974 & 423 & & 488 & 1176 & -40.4 & & 4.2 \\
\hline Stand & & & Pd & & & & & & Lk & & & \\
\hline No. & Stems & $\begin{array}{l}\text { Under } \\
\text { stems }\end{array}$ & $\begin{array}{c}\text { Crown } \\
\mathbf{s} \\
\end{array}$ & NTT & $\begin{array}{l}\text { NTT- } \\
\text { error }\end{array}$ & $\begin{array}{l}\text { NTT- } \\
\text { error2 }\end{array}$ & Stems & $\begin{array}{l}\text { Under } \\
\text { stems } \\
\end{array}$ & Crowns & s NTT & $\begin{array}{l}\text { NTT- } \\
\text { error }\end{array}$ & $\begin{array}{r}\text { NTT- } \\
\text { error2 }\end{array}$ \\
\hline 1 & 52 & 0 & 78 & 105 & 101.9 & 101.9 & 118 & 2 & 88 & 132 & 11.9 & 13.8 \\
\hline 2 & 252 & 0 & 159 & 297 & 17.9 & 17.9 & 31 & 0 & 97 & 182 & 487.1 & 487.1 \\
\hline 3 & 152 & 0 & 115 & 243 & 59.9 & 59.9 & 186 & 0 & 160 & 399 & 114.5 & 114.5 \\
\hline 4 & 299 & 0 & 118 & 465 & 55.5 & 55.5 & 88 & 0 & 146 & 285 & 223.9 & 223.9 \\
\hline 5 & 172 & 0 & 82 & 199 & 15.7 & 15.7 & 3 & 0 & 17 & 6 & 100.0 & 100.0 \\
\hline 6 & 146 & 0 & 56 & 272 & 86.3 & 86.3 & 18 & 0 & 54 & 103 & 472.2 & 472.2 \\
\hline 7 & 55 & 0 & 49 & 156 & 183.6 & 183.6 & 1 & 0 & 1 & 3 & 200.0 & 200.0 \\
\hline Total & 1128 & 0 & 657 & 1737 & 54.0 & 54.0 & 445 & 2 & 563 & 1110 & 149.4 & 150.6 \\
\hline
\end{tabular}


Table 4. Cont.

\begin{tabular}{ccccccccccccc}
\hline Stand & \multicolumn{3}{c}{ Cj } & \multicolumn{1}{c}{ BL } \\
\hline No. & Stems & $\begin{array}{c}\text { Under } \\
\text { stems }\end{array}$ & Crowns NTT & $\begin{array}{c}\text { NTT- } \\
\text { error }\end{array}$ & $\begin{array}{c}\text { NTT- } \\
\text { error2 }\end{array}$ & Stems & $\begin{array}{c}\text { Under } \\
\text { stems }\end{array}$ & Crowns NTT & $\begin{array}{c}\text { NTT- } \\
\text { error }\end{array}$ & $\begin{array}{c}\text { NTT- } \\
\text { error2 }\end{array}$ \\
\hline 1 & 0 & 0 & 1 & 0 & 0.0 & 0.0 & 224 & 83 & 70 & 174 & -22.3 & 23.4 \\
2 & 0 & 0 & 2 & 0 & 0.0 & 0.0 & 332 & 55 & 94 & 269 & -19.0 & -2.9 \\
3 & 73 & 54 & 0 & 0 & -100.0 & -100.0 & 260 & 111 & 45 & 55 & -78.8 & -63.1 \\
4 & 0 & 0 & 7 & 2 & - & - & 301 & 252 & 34 & 53 & -82.4 & 8.2 \\
5 & 35 & 7 & 18 & 16 & -54.3 & -42.9 & 195 & 55 & 63 & 121 & -37.9 & -13.6 \\
6 & 0 & 0 & 7 & 24 & - & - & 124 & 59 & 13 & 44 & -64.5 & -32.3 \\
7 & 3 & 3 & 2 & 2 & -33.3 & - & 67 & 26 & 8 & 45 & -32.8 & 9.8 \\
Total & 111 & 64 & 37 & 44 & -60.4 & -6.4 & 1503 & 641 & 327 & 761 & -49.4 & -11.7 \\
\hline
\end{tabular}

Stems: Count of trees from field survey; Under stems: Count of under storied trees from field survey; Crowns: Count of Crowns from image analysis; NTT: Count of treetops using new treetop technique by tree species from image analysis; NTT-error.: (NTT - Stems $) \div$ Stems $\times 100$; NTT-error2.: (NTT $-($ Stems - Under stems $)) \div($ Stems

- Under stems) $\times 100$.

These results show that the numbers of tree by species determined by the new treetop technique were less accurate than the total number of trees using the new technique. This may be due to the overestimation of $P$. densiflora, L. kaempferi, and broad-leaved trees compensating for the underestimation of $C$. obtusa and $C$. pisifera. Thus, this technique can be used effectively to extract the numbers of stems of upper and intermediate canopy trees in pure conifer plantations when multiple layers or high densities are not involved.

\section{Conclusion}

A method of counting the number of coniferous trees by species within forest compartments was developed by combining homogeneity-guided smoothing with tree detection, crown delineation and crown classification using high resolution four band airborne digital data. The image was divided by cover types using a homogeneity measure and smoothed according to predominant tree sizes. The small-crowned trees were smoothed using a mean filter of size $3 \times 3(1.5 \times 1.5 \mathrm{~m})$ while the larger upper-layer trees were smoothed even more with an additional $5 \times 5$ pixels filter $(2.5 \times 2.5 \mathrm{~m})$. This technique was effective across a range of forest stands, with most being dominated by conifer forest and older than 50 years.

The field verification process showed that the treetop detection with species information obtained using this new approach produced relatively high accuracies for a variety of stands. The accuracy of the new technique for the total number of trees per stand was higher than $84 \%$. This shows improvements over the individual tree crown delineation technique alone which had accuracies lower than $62 \%$, or the treetop detection technique alone which had accuracies lower than $78 \%$.

Forest GISs are now widely used in Japan to manage forest information on a stand polygon basis. The addition of stems by species to each stand polygon could become important for practical forest management operations such as precise thinning. This technique may allow objective maps to be easily created using GIS and may also be useful in allocating subsidies to forest planners. 
High-resolution airborne data are now being captured consistently on a five year cycle throughout Japan and the coverage continues to increase. In addition, the prevalence of this type of computer image analysis technique will be extended by the spread of some high resolution satellite data all over Japan. This new approach for assessing stand conditions and generating detailed forest databases may improve the management of conifer plantations in Japan.

There are some improved approaches for individual tree crown detection and delineation [21-23] and tree counting by species could attain higher accuracy by combining with these methods. Further application and testing are needed to extend our results to larger areas, multiple scenes, varied topographies and different forest conditions. Detailed one-on-one comparisons with field survey results will be required to better ascertain the ultimate accuracy of this new method. These are the subjects of ongoing research endeavors.

\section{Acknowledgments}

This study was supported by a Grant-in-Aid for Scientific Research from the Japan Society for the Promotion of Science (No. 21580178) and Adaptable and Seamless Technology Transfer Program through target-driven R\&D from JST (No. AS2212017E).

\section{References}

1. Forestry Agency. Annual Report on Trends in Forests and Forestry; Forest Agency, Ministry of Agriculture, Forestry and Fisheries of Japan: Tokyo, Japan, 2010.

2. Franklin, S.E. Remote Sensing for Sustainable Forest Management; Lewis Publisher, Boca Raton, FL, USA, 2001.

3. Hill, DA.; Leckie, D.G. Proceedings of the International Forum on Automated Interpretation of High Spatial Resolution Digital Imagery for Forestry; Pacific Forestry Centre, Canadian Forest Service: Victoria, BC, Canada, 1998.

4. Jensen, J.R. Remote Sensing of the Environment: An Earth Resource Perspective, 2nd ed.; Prentice-Hall: Englewood Cliffs, NJ, USA, 2007.

5. Leckie, D.G.; Gillis, M.D. Proceedings of the International Forum on Airborne Multispectral Scanning for Forestry and Mapping (with Emphasis on MEIS); Canadian Forest Service, Petawawa National Forestry Institute: Chalk River, ON, Canada, 1993.

6. Dralle, K.; Rudemo, M. Stem number estimation by kernel smoothing of aerial photos. Can. J. For. Res. 1996, 26:1228-1236.

7. Eldridge, N.R.; Edwards, G. Acquiring Localized Forest Inventory Information: Extraction from High Resolution Airborne Digital Images. In Proceedings of the 16th Canadian Symposium on Remote Sensing, Sherbrooke, QC, Canada, 7-10 June 1993; pp. 443-448.

8. Gougeon, F.A.; Moore, T. Classification individuelle des arbres à partir images à haute resolution spatiale. Télédétec. Gest. Ressour. 1989, VI, 185-196.

9. Gougeon, F.A.; Leckie, D.G. Forest Regeneration: Individual Tree Crown Detection Techniques for Density and Stocking Assessment. In Proceedings of the Forum on Automated Interpretation of High Spatial Resolution Digital Imagery for Forestry, Victoria, BC, Canada, 10-12 February 1998; pp. 169-177. 
10. Niemann, K.O.; Adams, S.; Hay, G. Automated Tree Crown Identification Using Digital Orthophoto Mosaics. In Proceedings of the Forum on Automated Interpretation of High Spatial Resolution Digital Imagery for Forestry; Hill, D.A., Leckie, D.G., Eds.; Canadian Forest Service: Victoria, BC, Canada, 1999; pp. 105-113.

11. Wulder, M.; Niemann, K.O.; Goodenough, D.G. Local maximum filtering for the extraction of tree locations and basal area from high spatial resolution imagery. Remote Sens. Environ. 2000, 73, 103-114.

12. Culvenor, D.S. Extracting Individual Tree Information. In Remote Sensing of Forest Environment: Concepts and Case Studies; Wulder, M., Franklin, S.E., Eds.; Kluwer Academic Publishers: Boston, MA, USA; Dordrecht, The Netherlands and London, UK, 2003; pp. 255-278.

13. Erikson, M.; Olofsson, K. Comparison of three individual tree crown detection methods. Mach. Vis. Appl. 2005, 16, 258-265.

14. Pollock, R. A Model-based Approach to Automatically Locating Individual Tree Crowns in High-Resolution Images of Forest Canopies. In Proceedings of the 1st International Airborne Remote Sensing Conference and Exhibition, Strasbourg, France, 11-15 September 1994; pp. 11-15.

15. Gougeon, F.A. A crown following approach to the automatic delineation of individual tree crowns in high spatial resolution aerial images. Can. J. Remote Sens. 1995, 21, 274-284.

16. Katoh, M.; Gougeon, F.A.; Leckie, D.G. Application of high-resolution airborne data using individual tree crown in Japanese conifer plantations. J. For. Res. 2009, 14, 10-19.

17. ERDAS. ERDAS Imagine 8.6 On-Line Help Manual; Available online: http://www.erdas.com/ service/support/ERDASSupport.aspx (accessed on 6 March 2012).

18. ESRI. Arcmap 9.3 and Spatial Analyst 9.3; Environment System Research Institute: Redlands, CA, USA, 2008.

19. Gougeon, F.A.; Leckie, D.G. Forest Information Extraction from High Spatial Resolution Images Using an Individual Tree Crown Approach; Information Report BC-X-396; Canadian Forest Service, Pacific Forestry Centre, Victoria, BC, Canada, 2003.

20. Geomatica 9. EASI User Guide; PCI Geomatics Enter. Inc.: Richmond, ON, Canada, 2005.

21. Pouliot, D.A.; King, D.J.; Pitt, D.G. Automated tree crown detection and delineation in high-resolution digital camera imagery of coniferous forest regeneration. Remote Sens. Environ. 2002, 82, 322-334.

22. Wang, L.; Gong, P.; Biging, G.S. Individual tree-crown delineation and treetop detection in high-spatial resolution aerial imagery. Photogram. Eng. Remote Sensing 2004, 70, 351-357.

23. Ke, Y.; Quackenbush. L.J. A comparison of three methods for automatic tree crown detection and delineation methods from high spatial resolution imagery. Int. J. Remote Sens. 2011, 32, $3625-3647$.

(C) 2012 by the authors; licensee MDPI, Basel, Switzerland. This article is an open access article distributed under the terms and conditions of the Creative Commons Attribution license (http://creativecommons.org/licenses/by/3.0/). 